\title{
Synergistic Effect of Potassium Iodide on Corrosion Inhibition of Mild Steel in HCl Medium by Extracts of Nypa Fruticans'Wurmb
}

\author{
${ }^{1 *}$ ORUBITE-OKOROSAYE, K; ${ }^{1} \mathrm{JACK}$, I R; ${ }^{1}$ OCHEI, M; ${ }^{2}$ AKARANTA, $\mathrm{O}$ \\ ${ }^{I}$ Department of Chemistry, Rivers State University of Science and Technology, Port Harcourt, Nigeria \\ ${ }^{2}$ Department of Pure and Industrial Chemistry, University of Port Harcourt, P. M. B. 5323, Port Harcourt, Nigeria
}

\begin{abstract}
The effect of Nypa fruticans' wurmb extract and the mixture of various concentration of KI and Nypa fruticans' wurmb extract on corrosion of mild steel in $0.1 \mathrm{M}$ and $0.5 \mathrm{M} \mathrm{HCl}$ have been investigated using weight loss methods. The study revealed that mild steel is more efficiently inhibited by Nypa fruticans' wurmb in the presence of KI than pure extract of Nypa fruticans' wurmb. The inhibition efficiencies increased with increased concentration of the additives. The highest inhibition efficiency of $77.31 \%$ was observed with single Nypa fruticans' wurmb extract. An improved inhibition efficiency of $95.36 \%$ was observed with the mixture of Nypa fruticans' wurmb extract and $\mathrm{KI}$ at $30^{\circ} \mathrm{C}$ in $0.5 \mathrm{M} \mathrm{HCl}$. Inhibition efficiency decreased with increase in temperature from $30-40^{\circ} \mathrm{C}$ but increased at relatively high temperature of $50^{\circ} \mathrm{C}$ an effect attributed to synergism between Nypa fruticans' wurmb extract and KI. The adsorption of inhibitor molecules on metal surface followed langmuir isotherm. Thermodynamic parameters such as heat of adsorption, $\Delta \mathrm{H}$, free energy of adsorption $\Delta \mathrm{G}$ and enthropy of adsorption are obtained from experimental temperatures ranging from $30-50^{\circ} \mathrm{C} . @ \mathrm{JASEM}$
\end{abstract}

Corrosion of metals has continued to receive attention in the technological world. Corrosion scientists are relentless in seeking better and more efficient ways of combating the corrosion of metals. Among other methods, adding inhibitors to the corrosion environment has been employed.The efficiency of these inhibitors is sometimes improved by the addition of some other compounds which act in synergism. Many studies have been carried out using synergistic corrosion inhibitors ( Beloglazow, 1989 and Ebenso et al,1999) to mention but a few. In the search for more environmentally friendly and readily available inhibitors, researchers have reported the use of local plants such as Vernonia Amygdalina (Loto, 1998), Lawsonia (El -ttre, et al 2005); among others. In line with these Nypa fruticans' wurmb a local plant has also been reported as inhibitor for mild steel in $\mathrm{HCl}$ medium (Orubite and Oforka 2004); which has similar inhibition properties with 1 , 5, Di-phenyl carbazone (Orubite and Oforka 2004); The inhibition efficiency of Nypa fruticans' wurmb on mild steel in $\mathrm{HCl}$ medium as reported in previous work could be improved. Reports (Guan Nan Mu, Xueming Li 2004); have shown that inhibition efficiency of an inhibitor can be improved by the addition of halide ions to the inhibitor, a process referred to as synergism. Synergistic inhibition effectively improves the inhibition efficiency of an inhibitor. It also results in decrease in amount of inhibitor used and diversification of application in corrosive media. Many investigations on synergistic inhibition are available in literature. Not much has been reported on the synergistic effects on naturally occurring inhibitors. Synergism between Nypa fruticans' wurmb and halide ions is not available in literature.
This paper investigates the synergistic inhibition between Nypa fruticans' wurmb extract and KI in $\mathrm{HCl}$ medium using weight loss method.

\section{MATERIALS AND METHODS}

Mild steel sheets of composition. They were cut in 5 $\mathrm{x} 4 \mathrm{~cm}$ components of $0.07-\mathrm{cm}$ thickness. The coupons were prepared as explained elsewhere (Loto, 1998). A total of 125 pieces of coupons were used.

Solutions: The corrosive medium was HCl. Standard solutions of different concentrations were prepared using distilled water $(0.1,0.5,1.0,1.5,2.0,3.0 \mathrm{M})$.

Nypa fruticans' wurmb extract: Nypa fruticans' wurmb extract was obtained as explained in previous work (Mohammedi et al 2004). A stock was prepared by dissolving $0.6 \mathrm{~g}$ of the extract in $1 \mathrm{dm}^{3}$ of $\mathrm{HCl}$. Thereafter concentrations of $0.06,0.09,0.15$, 0.24 and $0.36 \mathrm{gdm}^{-3}$ were obtained by dilution. Concentrations of KI prepared were $0.01,0.03$ and $0.05 \mathrm{M}$

Weight loss measurement: A set of six $250 \mathrm{ml}$ beakers containing $0.1,0.5,1.0,1.5,2.0,3.0 \mathrm{M} \mathrm{HCl}$ solution for $30^{\circ} \mathrm{C}$ and another set of six of same concentrations for elevated temperatures of 40 and $50^{\circ} \mathrm{C}$ were used. A thermostated water bath was used to maintain the temperatures. The coupons were washed several times with distilled water, rinsed in ethanol, dipped in acetone and dried using a stream of air and left in a desicator before weighing. After weighing accurately the coupons were immersed in $250 \mathrm{ml}$ beakers each containing $200 \mathrm{ml}$ of hydrochloric acid with and without additives. The coupons were retrieved every $24 \mathrm{hrs}$ for 7 days (168 hrs.).

*Corresponding author: 
Each set dipped into a washing solution which terminates the corrosion reaction. The weight loss of mild steel coupons was evaluated in grams as the difference in the weight of the coupons before and after the test.

$$
W_{g}=\left(W_{i}-W_{f}\right)
$$

$\mathrm{W}_{\mathrm{i}}=$ initial weight of coupon; $\mathrm{W}_{\mathrm{f}}=$ final weight of coupon; $\mathrm{W}_{\mathrm{g}}=$ weight loss of coupon

Each reading reported is an average of three experimental reading recorded to the nearest $0.001 \mathrm{~g}$ on a mettler AE166 analytical balance.

\section{RESULTS AND DISCUSSION}

Effect of corrodent concentration: It was confirmed that mild steel corrodes in $\mathrm{HCl}$ solution. As earlier reported weight loss depended on $\mathrm{HCl}$ concentration and temperature Fig. I show the variation of weight loss with time at different temperatures and concentrations.

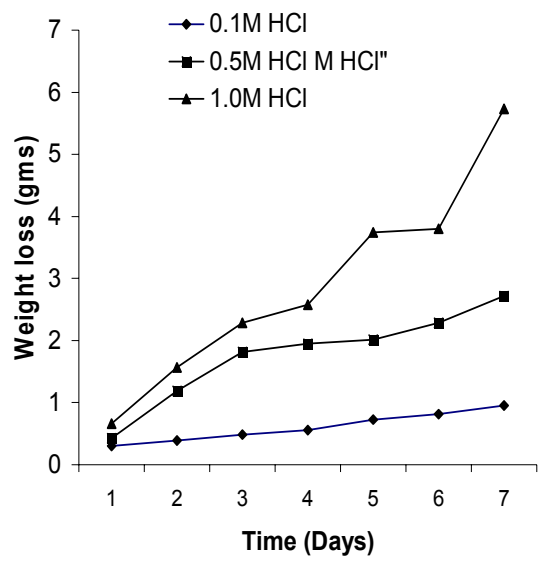

Fig. 1 Weight loss of mildsteel in various concentratons of $\mathrm{HCl}$ at $30^{\circ} \mathrm{C}$

Effect of addition of Nypa fruticans' wurmb extract to corrosion medium: Corrosion inhibition studies were done in $0.1 \mathrm{M}$ and $0.5 \mathrm{M} \mathrm{HCl}$. It was observed that weight loss of coupon decreased when Nypa fruticans' wurmb was added to the corrosion media. Corrosion rate also decreased as evident in Fig. 2. Corrosion rate was calculated from the equation:

$C r=\frac{534 W}{D A T}$

$\mathrm{W}=$ weight loss $(\mathrm{mg}) ; \mathrm{D}=$ density of coupon $\left(\mathrm{gcm}^{-}\right.$ $\left.{ }^{1}\right) ; \mathrm{A}=$ Area of coupon $\left(\mathrm{cm}^{2}\right) ; \mathrm{T}=$ Exposure Time (hrs.)

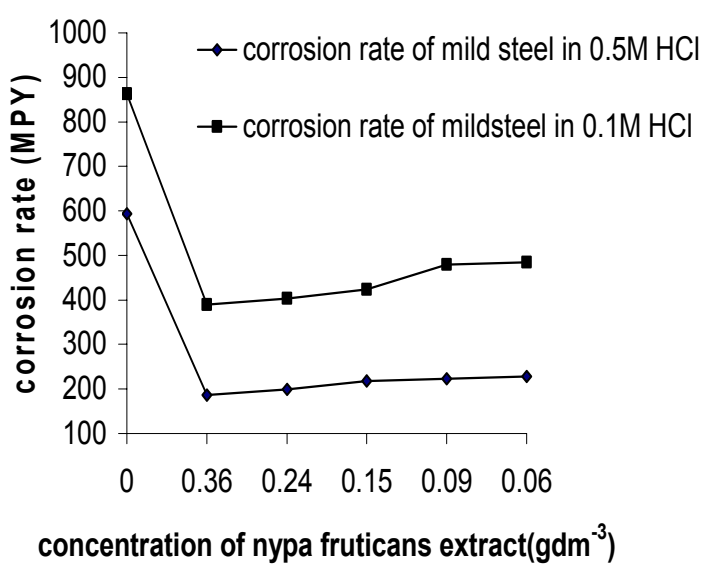

Fig. 2 Corrosion rate of mild steel with and without nypa fruticans' extract in $0.1 \mathrm{M}$ and $0.5 \mathrm{M} \mathrm{HCl}$

The inhibition efficiency of Nypa fruticans' wurmb was expressed in terms of percentage inhibition, calculated using the equation,

$$
{ }_{-} \% E=100 X\left[\frac{W_{o}-W_{a}}{W_{o}}\right]
$$

$\mathrm{W}_{\delta}=$ weight loss without additive; $\mathrm{W}_{\mathrm{a}}=$ weight loss with additive

As shown in Fig 3, the maximum percentage inhibition of $74.23 \%$ and $77.31 \%$ were recorded for $0.5 \mathrm{M}$ and $0.1 \mathrm{M}$ respectively at $30^{\circ} \mathrm{C}$. Inhibition efficiency was observed to increase with increase in concentration of Nypa fruticans' wurmb extract and decrease with increasing temperature.

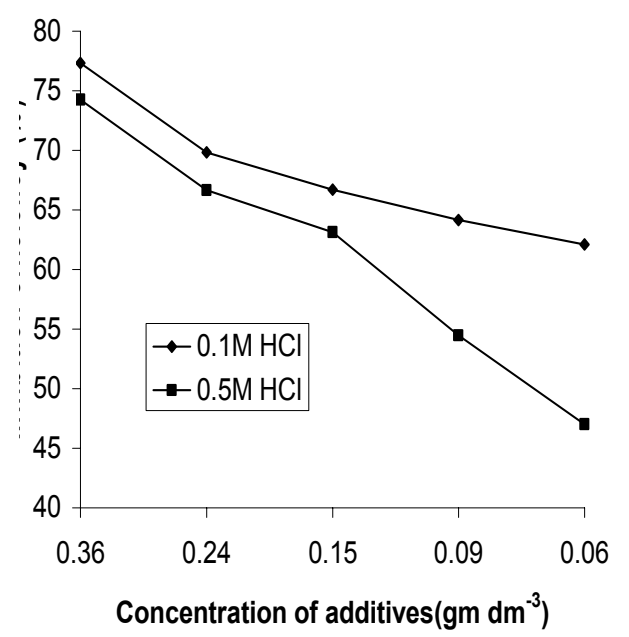

Fig. 3 Variation of inhibition efficiency with concentration of additives in $0.1 \mathrm{M}$ and $0.5 \mathrm{M} \mathrm{HCl}$ at $30^{\circ} \mathrm{C}$

Effect of addition of KI to Nypa fruticans' wurmb extract to corrosion media: As shown in Fig. 4, the 
introduction of KI to Nypa fruticans' wurmb extract reduced further the weight loss of mild steel coupons in the acid medium. Whereas a weight loss of 0.1353 $\mathrm{g}$ was recorded with only $0.36 \mathrm{gdm}^{-3}$ of Nypa fruticans' wurmb extract, the weight loss reduced to $0.0125 \mathrm{~g}$ with the addition of $\mathrm{KI}$ at the same temperature of $30^{\circ} \mathrm{C}$. Same was true for all the concentrations studied. In $0.1 \mathrm{M} \mathrm{HCl}$ an inhibition efficiency of $77.31 \%$ was obtained for only Nypa fruticans' wurmb but the inhibition efficiency increased to $95.36 \%$ with the inclusion of KI to Nypa fruticans' wurmb extract. The inhibition power of the mixture was found to be more effective at higher concentrations $\left(0.36 \mathrm{gdm}^{-3}\right.$ Nypa fruticans' $+0.05 \mathrm{M}$ $\mathrm{KI}$ ) as $95.36 \%$ than at lower concentrations $0.18 \mathrm{gdm}$ $3+0.01 \mathrm{M} \mathrm{KI}) 91.01 \%$. The observations clearly establish that the addition of $\mathrm{KI}$ improved the corrosion inhibition power of Nypa fruticans' wurmb extract.

Effect of temperature of inhibition on additives: With only Nypa fruticans' wurmb, it was observed that inhibition efficiency decreased with increase in temperature; a situation that is generally true of most chemical reactions. However addition of $\mathrm{KI}$ to the Nypa fruticans' wurmb extract showed a slightly different trend.For all the different concentrations of $\mathrm{KI}$ added to the highest concentration of Nypa fruticans' wurmb extract $\left(0.36 \mathrm{gdm}^{-3}\right)$ inhibition efficiency decreased as temperature increased from $30-40^{\circ} \mathrm{C}$ but showed a dramatic increase at the highest temperature of $50^{\circ} \mathrm{C}$ (fig. 5). As shown in figure 4 for the mixture of $0.01 \mathrm{M} \mathrm{KI}+0.36 \mathrm{gdm}^{-3}$ Nypa fruticans' wurmb inhibition efficiency was $93.86 \%$ at $30^{\circ} \mathrm{C}, 83.08 \%$ at $40^{\circ} \mathrm{C}$ and 87.74 at $50^{\circ} \mathrm{C}$. This observation has been attributed to synergistic inhibition between Nypa fruticans' wurmb extract and KI for mild steel corrosion in the acid medium. Similar observations have been reported.

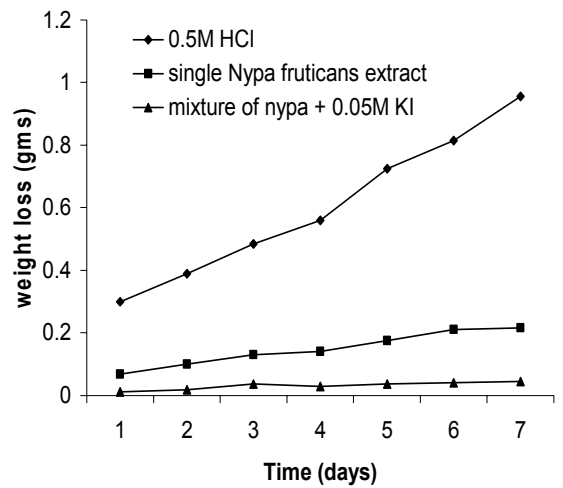

Fig 4 Weight loss of mild steel in $0.5 \mathrm{M} \mathrm{HCl}$ with various concetration of additives at $30^{\circ} \mathrm{C}$

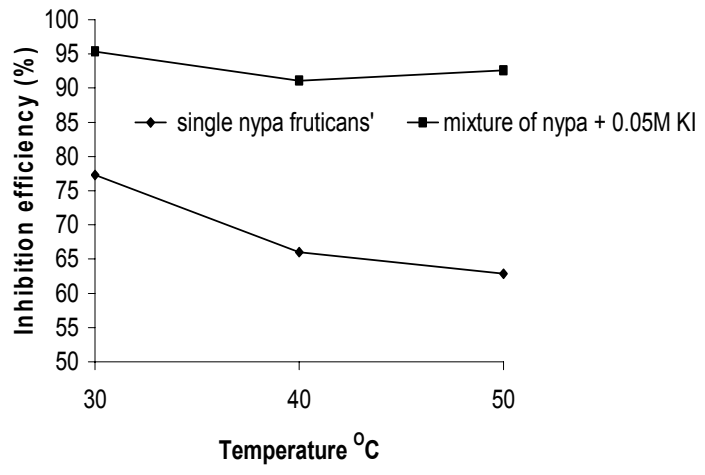

Fig. 5 Variation of inhibition efficiency (\%) with temperature

Adsorption isotherm: Surface coverage values are calculated on the assumption that inhibition is as a result of adsorption on metal surface. As evident in the figure, surface coverage (ø) increased with increase in concentration of single Nypa fruticans' wurmb extract or mixture of Nypa fruticans' wurmb and KI at each experimental temperature. The adsorption of inhibitor may have formed monolayer coverage between the metal and the corrosive environment. Hence as the concentration increased, the fraction of the mild steel surface covered by the adsorbed molecules (ø) increased leading to higher inhibition efficiency.

Using the expression, $C / \theta=1 / K+C$

$\mathrm{C}=$ oncentration of inhibitor; $\theta=$ surface coverage

The regression between $\mathrm{C} / \theta$ and $\mathrm{C}$ at different temperatures gave a linear graph (Fig 6) an indication that the adsorption of the inhibitors on mild steel surface follows Lanqunuir isotherm. The figure shows that the surface coverage decreased as temperature increased from $30-40^{\circ} \mathrm{C}$ but at higher temperature of $50^{\circ} \mathrm{C}, \theta$ increased. The explanation may be that at this temperature, some adsorbed molecules desorbed into the metal and became part of it.

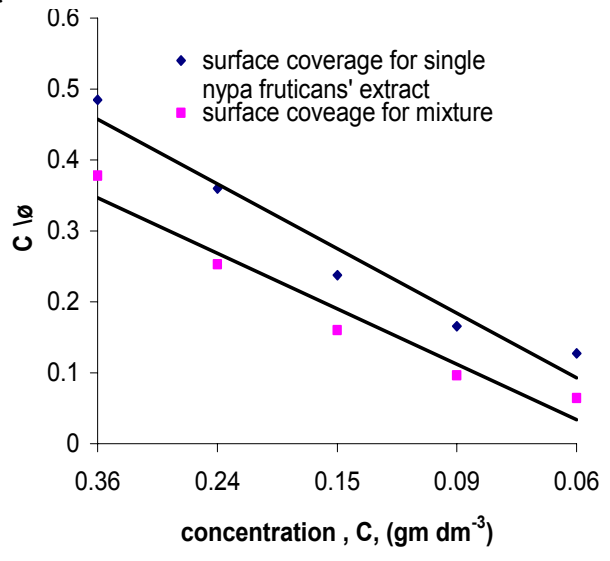

Fig. 6 Regression between $\mathrm{C}$ løand $\mathrm{C}$ at $30^{\circ} \mathrm{C}$ 
Thermodynamic Parameters: The adsorption phenomenon proposed was explained by calculating thermodynamic parameter. From the adsorption coefficient $(\mathrm{K})$ obtained the heat of adsorption, $\left(\Delta \mathrm{H}^{\circ}\right)$, free energy of adsorption $\left(\Delta \mathrm{G}^{0}\right)$ and Enthropy of adsorption $\left(\Delta \mathrm{S}^{\circ}\right)$ were calculated and are presented in Table 1. Under experimental conditions, heat of adsorption can be approximately regarded as standard heat of adsorption. It signifies the heat content of the reaction at constant temperature. According to Van't Hoff equation.

$$
\operatorname{In} K=\frac{-\Delta H_{a d}}{R T}+\text { cons } \tan t
$$

A negative $\Delta \mathrm{H}$ value suggests an exothermic reaction while positive value indicates an endothermic reaction. A negative slope reveals that the adsorption coefficient, $\mathrm{K}$, gets smaller with temperature rise. $\Delta \mathrm{H}$ values calculated predict an endothermic reaction. The standard free energy of adsorption $\Delta \mathrm{G}^{0}$ is related to the equilibrium constant of adsorption $\mathrm{K}$. Thus $\Delta G^{0}$ was calculated by the equation; $K=\frac{1}{55.5} \exp \frac{-\Delta G}{R T}$

Where $\Delta \mathrm{G}^{\mathrm{o}}=$-RT In $55.5 \mathrm{~K}$

Calculated $\Delta \mathrm{G}^{0}$ values were negative suggesting that there was a strong adsorption of the inhibitor molecules on the mild steel surface. Enthropy can be visualized in terms of the number of ways in which energy may be stored by a molecule or molecules as well as in terms of degree of randomness. It measures the chaotic dispersal of energy. The natural tendency of spontaneous change is towards state of higher enthropy. Enthropy of adsorption was obtained from the relationship. $\Delta G^{o}=\Delta H^{o}-T \Delta S . \quad$ The positive values obtained for $\Delta \mathrm{S}$ indicate that the adsorption is accompanied by an increase in enthropy.

Table 1: Calculated thermodynamic parameters.

\begin{tabular}{cccc}
\hline Temp. & $\Delta \mathrm{G}^{\mathrm{o}}$ & $\Delta \mathrm{H}^{\mathrm{o}}$ & $\Delta \mathrm{S}^{\mathrm{o}}$ \\
\hline 30 & -23.2112 & 24.9420 & 165.5221 \\
40 & -23.1843 & 24.9420 & 153.7581 \\
\hline 50 & -25.0139 & 24.9420 & 154.6622 \\
\hline
\end{tabular}

Proposed mechanism of inhibitive action of additives: The result obtained show that single Nypa fruticans' wurmb extract and mixture of Nypa fruticans' wurmb extract and $\mathrm{KI}$ in synergism were good inhibitors for corrosion of mild steel in $\mathrm{HCl}$ medium. Tannins or nitrogenous compound have been proposed ${ }^{4}$ to be present in Nypa fruticans' wurmb extract and responsible for the formation of passivating layer of tannates on metal surface. Tannins are known to form complex compounds with different metal cations and for this reason, they are used in the manufacture of anti-rusting paints. Nitrogenous compounds like amine type inhibitors effect corrosion inhibition through an unshared pair of electrons belonging to the nitrogen atom. In the present study the synergistic effect produced by the addition of iodide ions can be explained on the basis that iodide ions like all halide ions have the ability to function as ligands as well as mixed complexes along with other ligands. In the acid solution, Nypa fruticans' wurmb extract may have been protonated to the form,

$$
\mathrm{Nypa}-\mathrm{N}+\mathrm{H}^{+} \Leftrightarrow \mathrm{NypaNH} \mathrm{H}^{+}
$$

Mild steel surface contains positive charges in the acid solution. The protonated Nypa fruticans' wurmb extract would not attach to the mild steel surface because of repulsive interaction with the mild steel surface. In the presence of iodide ions this protonated complex combines with iodide ions to form a negatively charged complex ion, through electrostatic interaction between $\mathrm{I}^{-}$and protonated complex. The resultant negatively charge complex ion thus attaches to mild steel surface and forms a film as barrier between metal surface and the acid solution. This film could be insoluble at lower temperatures $30^{\circ} \mathrm{C}$ and dissolves as temperature increases from $30-40^{\circ} \mathrm{C}$ hence the decrease in inhibition efficiency as temperature increased. The reason for the increase in inhibition efficiency at $50^{\circ} \mathrm{C}$ could be that some of the inhibitors molecules desorbed into the metal surface to constitute an added barrier to the $\mathrm{HCl}$ medium. Therefore, both physical adsorption and chemical adsorption could be proposed as been responsible for the corrosion inhibition of mild steel by mixture of Nypa fruticans' wurmb extract and $\mathrm{KI}$ in $\mathrm{HCl}$ medium.

Conclusion: Nypa fruticans' wurmb extract inhibits the corrosion of mild steel in $\mathrm{HCl}$ medium. The addition of KI in various Nypa fruticans' wurmb fruticans' wurmb through synergistic inhibition between Nypa fruticans' wurmb and KI. The adsorption on mild steel surface by inhibitor molecules, obey langmuir isotherm. The adsorption is a spontaneous endothermal process which is accompanied by an increase in enthropy. Physical and chemical adsorption process has been proposed. At higher experimental temperature, inhibitor molecules are desorbed into the metal surface.

\section{REFERENCES}


Beloglazow,S.W; (1989):Organic inhibitors of hydrogen embrittlement, chemical science index, USA vol. 19, 903

Ebenso, F.E; Ekpe, U.J Offiong, O.E; and Ibok,(1999); Effects of molecular structure on the efficiency of amides and thiosemicarbazones used for corrosion inhibition of mild steel in $\mathrm{HCl}$. Mar. chem. and phy, vol. 60,79-90

El -ttre, A.Y; Abdallah, M; El- Tantawy, Z.E (2005); Corrosion inhibition of some metals using lawsonia Science, 47,385-395

Guan Nan Mu, Xueming Li (2004); Synergistic inhibition between $\mathrm{o}-$ phenanthroline and chloride ion on cold rolled steel corrosion inphosphoric acid. Mat. Chem. and phy. 86, 5968

Loto, C A; ( 1998); The effect of vernonia amygdalina (bitter leaf) extracts on corrosion of mild steel in $0.5 \mathrm{M} \mathrm{HCl}$ and $\mathrm{H}_{2} \mathrm{SO}_{4}$ solutions, Niger. Corr. J. I (1) 19-20

Mohammedi, A; Benmoussa, C F; Sutter, E.M.M; (2004) Synergistic or additive corrosion inhibition of mild steel by a mixture of HEDP and metasilicate at $\mathrm{pH} 7$ and 11. Mat and Corros, 55,11 .

Orubite, K O; Oforka, N C; (2004),Inhibition of corrosion of mild steel in $\mathrm{HCl}$ solutions by the extracts of leaves of Nypa fruticans' wurmb Mat. letters 58,1768-1772

Orubite, K O; Oforka, N C (2004), Corrosion inhibition of zinc in $\mathrm{HCl}$ using Nypa fruticans' wurmb extract and1,5 Diphenylcarbazone. J. Appl. Sci. Environ, Mgt. vol. 8 (1) 57-61

Tang,L B; Liu, G H; (2004) Corros. Sci. 45, 2251

Zhang, D.Q; Gao; Zhou, G.D;(2003); J. Appl. Electrochem. 33, 36 